\title{
Scientists' warning on endangered food webs
}

\author{
Ruben H. Heleno ${ }^{1}$, William J. Ripple ${ }^{2}$, and Anna Traveset $^{3}$ \\ ${ }^{1}$ Centre for Functional Ecology, Department of Life Sciences, University of Coimbra, \\ 3000-456 Coimbra, Portugal \\ ${ }^{2}$ Global Trophic Cascades Program, Department of Forest Ecosystems and Society, \\ Oregon State University, Corvallis, Oregon 97330, USA \\ ${ }^{3}$ Global Change Research Group, Instituto Mediterráneo de Estudios Avanzados, CSIC-UIB, \\ 07190 Esporles, Mallorca, Spain \\ Correspondence: Ruben H. Heleno (rheleno@uc.pt)
}

Received: 13 January 2020 - Revised: 23 February 2020 - Accepted: 3 March 2020 - Published: 3 April 2020

\begin{abstract}
All organisms are ultimately dependent on a large diversity of consumptive and non-consumptive interactions established with other organisms, forming an intricate web of interdependencies. In 1992, when 1700 concerned scientists issued the first "World Scientists' Warning to Humanity", our understanding of such interaction networks was still in its infancy. By simultaneously considering the species (nodes) and the links that glue them together into functional communities, the study of modern food webs - or more generally ecological networks - has brought us closer to a predictive community ecology. Scientists have now observed, manipulated, and modelled the assembly and the collapse of food webs under various global change stressors and identified common patterns. Most stressors, such as increasing temperature, biological invasions, biodiversity loss, habitat fragmentation, over-exploitation, have been shown to simplify food webs by concentrating energy flow along fewer pathways, threatening long-term community persistence. More worryingly, it has been shown that communities can abruptly change from highly diverse to simplified stable states with little or no warning. Altogether, evidence shows that apart from the challenge of tackling climate change and hampering the extinction of threatened species, we need urgent action to tackle large-scale biological change and specifically to protect food webs, as we are under the risk of pushing entire ecosystems outside their safe zones. At the same time, we need to gain a better understanding of the global-scale synergies and trade-offs between climate change and biological change. Here we highlight the most pressing challenges for the conservation of natural food webs and recent advances that might help us addressing such challenges.
\end{abstract}

The "interdependent web of life"

In 1992, when scientists from around the world issued the first "World Scientists' Warning to Humanity" (UCS, 1992) they already emphasized the importance of protecting what they called the "interdependent web of life (...) whose interactions and dynamics we only imperfectly understand". Interestingly, this call simultaneously highlighted the great importance of and our assumed ignorance about the complex web of biological interactions that support life on Earth. Perhaps due to the intrinsic difficulties of delivering strong predictions regarding the stability and functioning of such interdependent webs, over the last 30 years, the need to halt climate change and protect threatened species has been the focus of most media attention. But during this period, scientists have fully embraced the quest of understanding the structure and dynamics of the underlaying web of life and produced staggering advances (e.g. Bascompte and Jordano, 2007; Poisot et al., 2013; Thompson et al., 2012). We are thus now in a much better position to evaluate the status of the world's food webs, and the news is not reassuring. 
2 All life is imbedded in a complex web of interactions

After centuries of cataloguing life on Earth and nearly 2 million species named and described, many groups remain very poorly known and we are still far from knowing how many species there are on the planet (Scheffers et al., 2012). At the same time, increasing demand for food, water, timber, fuels, and minerals, to meet the needs of a rapidly growing human population, has changed ecosystems more rapidly and extensively in the last 50 years than ever before, resulting in a rapid loss of biodiversity (Barnosky et al., 2011; IPBES, 2019). As a result, we are losing species much faster than the background extinction rate (Ceballos et al., 2015), with many species going extinct before they are recorded by scientists and, what is more disturbing, before we have any idea of the role they play in their ecosystems.

We have known for a long time that no organism can survive and reproduce without interacting with other organisms around it (Fig. 1). Most of these interactions reflect the need to access energy to keep the metabolism working, and these include all trophic interactions, such as predation, herbivory, or parasitism. While these interactions are only beneficial for one of the species involved, other interactions are mutually beneficial, such as the pollination of flowering plants by insects or the dispersal of their seeds by frugivorous animals. But there is still a myriad of other interaction types that vary greatly on their net effect for the species involved, including obligatory symbiosis between algae and fungi that cannot survive in isolation (e.g. Pogoda et al., 2018), birds that always build their nests on the same plant species (e.g. Millington and Grant, 1983), or seeds that cannot germinate unless they find the right mycorrhizal fungi (e.g. Bidartondo, 2005). It is now clear that the linear food chains we learned about in school are actually a gross simplification of the countless vertical and horizontal, antagonistic and mutualistic interactions spanning multiple spatial and temporal scales, frequently known as food webs or more generally as ecological networks (Bascompte and Jordano, 2013).

Ecologists were well aware of the importance of food webs in structuring natural ecosystems even before ecology emerged as a discipline (e.g. Darwin, 1859); however, until recently, we simply lacked the tools that allowed us to make sense of the apparent mess of biotic interactions (Lawton, 1995). The incorporation of analytical tools from neighbouring disciplines and their refinement within the realm of ecology have provided such framework, creating a rapidly developing field that quantitatively explores the patterns and mechanisms responsible for food web assembly and disassembly (Bascompte and Jordano, 2007). The great tweak of the network approach is that it expands the traditional emphasis on taxonomic species into interaction matrices that simultaneously quantify the species (nodes) and the links (edges) that glue them together into functional communities, thus providing a privileged viewpoint from where one can simultaneously see the forest and the trees, metaphorically speaking (Heleno et al., 2014).

Although the field was still incipient at the time the first World Scientists' Warning to Humanity (UCS, 1992), since then we have learned a great deal about the structure of food webs and how it relates to community functioning and persistence (Bascompte and Jordano, 2007; Fontaine et al., 2006; Pocock et al., 2012; Rumeu et al., 2017; Tylianakis et al., 2010). We have studied food web resilience to various global change stressors and identified common patterns, and it is clear that the consequences of global change cannot be accurately predicted by simply summing up the isolated effects it has on each species. Indeed, understanding how the responses of pairwise interactions scale up to shape the responses of entire communities to global change remains one of the great scientific challenges of our times (Bascompte, 2009). It has also become evident that by losing species we lose more than just a Latin binomial name of the board; we also lose the functions that those species performed in the ecosystem they are integrated in and upon which we ultimately depend (Kremen and Hall, 2005). By maintaining high levels of biodiversity via a myriad of bottom-up and topdown effects, biotic interactions are directly and indirectly responsible for most services we derive from nature. These services include the provision of food, fuel, shelter, pest control, flood regulation, water quality, pollination, seed dispersal, soil production, carbon storage, nutrient cycling, recreation, inspiration, and many others (MEA, 2005), to the point that the resilience of natural food webs are directly or indirectly related to many UN Sustainable Development Goals (UN, 2015).

Nearly 30 years ago, 1700 concerned scientists issued a first warning to humanity highlighting the pressing need to rethink the way that humanity interacts with the natural word so as to avoid a collision with unknown effects (UCS, 1992). Recently, a second warning was issued and signed by more than 15000 scientists from 187 countries stating that "To prevent widespread misery and catastrophic biodiversity loss, humanity must practice a more environmentally sustainable alternative to business as usual" (Ripple et al., 2017). Here we take a broader view of biodiversity and elaborate over the state of the world's food webs, their capacity to withstand external threats, and the detection of early-warning signals of eventual food web collapse.

\section{The architecture of biodiversity}

Whether biological communities have a highly predictable structure or whether they are better portrayed as a random association of co-occurring species is a question as old as ecology. Depicting communities as sets of nodes and links allowed the identification of a set of emergent patterns shared by most biological communities that distinguish them from random species assemblages and define an underly- 


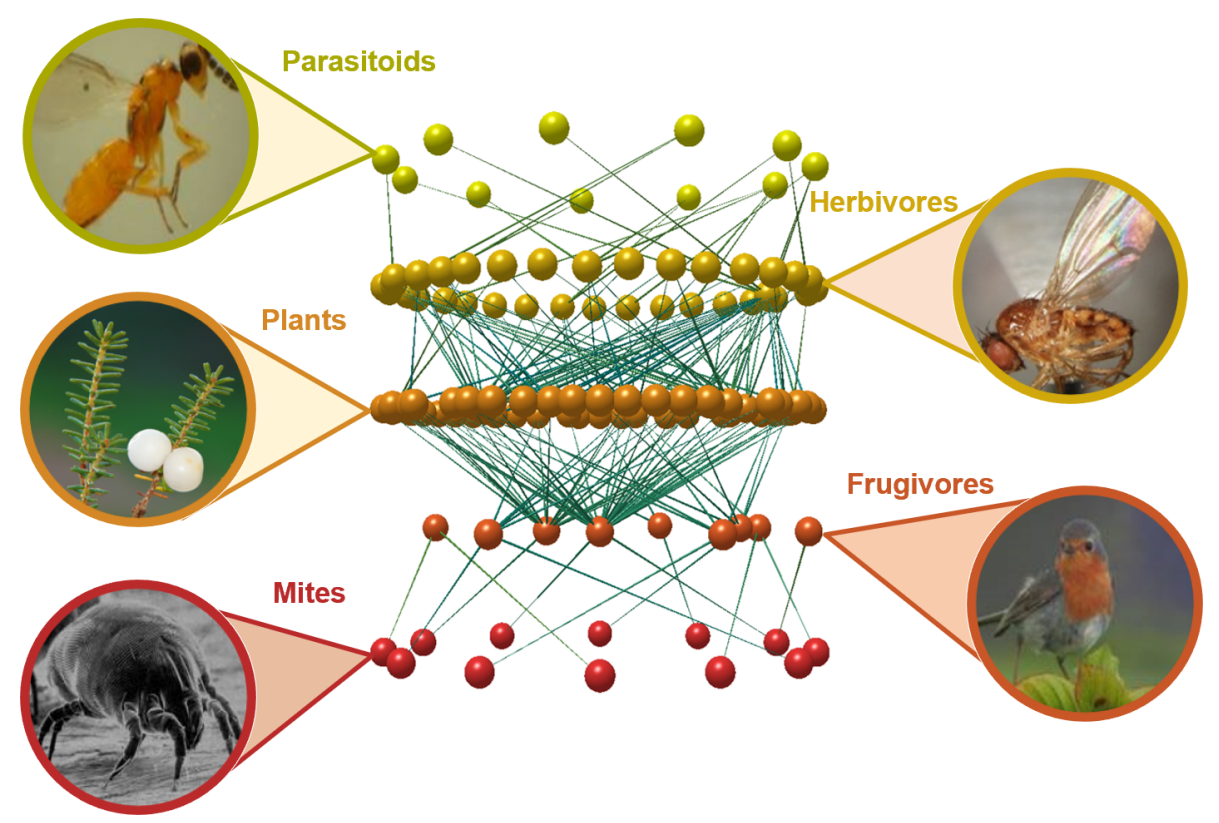

Figure 1. Fragment of an Azorean food web and the biotic interactions linking plants, herbivores, their parasitoids and frugivorous birds, and their external parasites. The network visualization was built with the software Network3D (Williams, 2010) based on data from Heleno et al. (2013) and Heleno et al. (2010).

ing "biostructure" (McCann, 2007) or the "architecture of biodiversity" (Bascompte and Jordano, 2007). At least three interrelated properties emerge from most food webs. First, there is a dominance of generalist interactions, such that the tight specialization between two species is extremely rare in nature (Pimm et al., 1991). Secondly, most interactions are highly asymmetrical; i.e. if species A depends strongly on species $\mathrm{B}$, the reciprocal dependence is rarely observed (Bascompte et al., 2006). Thirdly, the overall interaction matrix usually follows a nested pattern in which the interactions established by the most specialized species tend to be a particular subset of the interactions established by the most generalist species in a hierarchical (i.e. Russian-dolllike) pattern (Bascompte et al., 2003). Empirical and theoretical work showed that this hierarchical arrangement of interactions protects communities against the random loss of species by creating a redundancy (i.e. backup) system that buffers against lost interactions (Verdú and Valiente-Banuet, 2008). However, as most species in a highly nested network interact directly with a core of generalist species, this generates a "small world" effect (Watts and Strogatz, 1998), which can also have negative implications on network stability, namely by accelerating the spread of diseases or facilitating the spread of invasive species (James et al., 2012; Rohr et al., 2014; Traveset and Richardson, 2014).

\section{Patterns and mechanisms of food web disruption}

As biotic interactions are frequently lost at a much faster pace than species, several forms of anthropogenic disturbances as- sociated with global change have been documented to simplify food web structure far beyond the linear loss of species themselves (Valiente-Banuet et al., 2015). At first glance, such decoupling might seem intuitive and relatively unimportant; however it can lead to the accumulation of "ghost species" - extant species that already lost the biotic resources they need for long-term persistence, thus originating an extinction debt to be collected in the form of inevitable secondary extinctions (Tilman et al., 1994; Valiente-Banuet et al., 2015). Such effects can be even more worrying as species might stop playing their functional roles in ecosystems, i.e. become functionally extinct, well before their actual extinction (Anderson et al., 2011).

We must make no mistake: we are seeing one of the great historical convulsions in the world's fauna and flora (Charles Elton 1958).

By allowing us to model the probability of secondary extinctions and the capacity of food webs to withstand biodiversity losses before they happen, network approaches have greatly improved our understanding of community responses to global change stressors (Pocock et al., 2012; Rumeu et al., 2017). If extinctions were random, i.e. an unselective pruning of the entire community, their main consequence would be a gradual decrease in overall diversity with only moderate effects on the intrinsic community structure. However, current extinctions have been repeatedly shown not to be random but oriented towards particularly vulnerable groups, namely species with large home ranges, large body size, long lifespan, low reproductive rate, specialists, and species of higher 
trophic levels (Gardner et al., 2011; Ledger et al., 2013; Ripple et al., 2014, 2015; Vidal et al., 2014). Some of the traits that make these groups vulnerable to extinctions also make them disproportionately important for the structure of food webs, such that these non-random changes have a very strong potential to drastically change entire communities (Memmott et al., 2004; Montoya et al., 2006; Ripple et al., 2015; Rumeu et al., 2017; Woodward et al., 2012).

\subsection{Patterns}

Most anthropogenic stressors associated with global change have been shown to affect food webs in multiple ways (reviewed in Traveset et al., 2018; Tylianakis and Morris, 2017), usually with net negative effects on species, interactions, and a simplification of network structure (Tylianakis et al., 2008). Our goal here is not to provide a systematic review of these effects but to pinpoint some of the main mechanisms by which global change stressors have been shown to affect food webs.

Among all stressors, the effects of rising temperature and biological invasions received most attention. Temperature directly affects organisms' metabolic rate, for example by favouring $\mathrm{C}_{4}$ plants (Zavaleta et al., 2003), with likely implications for entire food webs (Moya-Laraño et al., 2012). Field experiments have shown that different trophic groups will likely respond differently to increased temperature, yet consistently leading to a simplification of the food web either in agricultural fields (Derocles et al., 2018), grasslands (de Sassi et al., 2012) or in streams (O'Gorman et al., 2012). Biological invasions also have a well-demonstrated potential to disrupt local food webs. One of the most striking examples has been documented on the island of Guam, where the introduction of the brown tree snake (Boiga irregularis) rapidly decimated the populations of birds, bats, and reptiles, negatively affecting pollination and seed dispersal services to plants, with detrimental consequences for plant recruitment (Rogers et al., 2017). Similarly, the introduction of invasive alien plants can also simplify herbivory networks (Heleno et al., 2009), often with cascading effects to higher trophic levels (López-Núñez et al., 2017). Pollination networks are also affected by the arrival of super-generalist invasive species, although changes on overall food web structure have been hard to identify (Traveset et al., 2015; Vilà et al., 2009). Other stressors, such as agriculture intensification and habitat fragmentation have also been shown to simplify plant-animal interactions, usually by concentrating energy flow along fewer pathways in intensively managed landscapes (Albrecht et al., 2007; Morrison et al., 2020; Tylianakis et al., 2008, 2007). Urbanization is also known to affect natural food webs (Faeth et al., 2005); however generalization on the magnitude or direction of such effects is still not really possible due to the difficulty of disentangling the effects from multiple associated drivers, the variability in the concept of urbanization, and paucity of studies. Finally, elevated atmospheric $\mathrm{CO}_{2}$, eutrophication, deforestation, drought, and over-exploitation have all been shown to simplify food webs or at least to have the potential to do so (Laliberté and Tylianakis, 2010; Ledger et al., 2013; Stiling and Cornelissen, 2007; Woodward et al., 2012).

While long-term datasets to monitor community-level changes are rarely available, fishery records from the last 70 years show unambiguous changes in entire marine food webs. These changes are driven by a selective exploitation of large fish from high trophic levels and reflect a steady decline in the mean trophic level of captures as fishing efforts progressively shift to the lower trophic levels when higher trophic level populations are depleted (MEA, 2005). Such consumptive and non-consumptive effects often propagate downwards and upwards across multiple trophic levels, generating "trophic cascades" (López-Núñez et al., 2017; Ripple and Beschta, 2006; Ripple et al., 2016) that have been collectively referred to as the trophic downgrading of planet Earth (Estes et al., 2011).

\subsection{Mechanisms}

Due to the intrinsic difficulty of experimentally inducing community-wide changes, empirical studies still lag behind theoretical predictions regarding food web collapse. However, evidence for a simplification of food webs due to the action of global change stressors is now unsurmountable (Tylianakis and Morris, 2017). Such effects are mediated by non-random changes in species encounter probabilities, which can be triggered by three broad mechanisms. First, several climate change drivers can affect species phenology, reducing the temporal windows during which interactions are possible and creating temporal mismatches between resources and consumers. Such mismatches are particularly worrying in temperate regions, where animal life cycles tend to be aligned with the period of maximum available resources for reproduction, growth, molt, or migration. In particular, the consistent anticipation of spring events over the last few decades has been followed by an anticipation of the phenological cycles of many plants and animals (Hegland et al., 2009; Parmesan and Yohe, 2003). Although many consumers are able to track the shifting phenology of their resources (e.g. Sparks and Yates, 1997), many others cannot, leading to documented mismatches between caterpillars and nesting birds (Visser et al., 2006), between roe deer birth date and vegetation flush (Plard et al., 2014), or between flowering and pollinators (Memmott et al., 2007). Another important way by which climate change generates phenological mismatches is by disrupting the timing of animal migrations with the availability of their key resources (Mayor et al., 2017).

Secondly, by rearranging species distributions, climate change is already affecting species encounter probabilities, leading to the spatial decoupling of biotic interactions (Lurgi et al., 2012). Global warming is directly promoting poleward range shifts of many species, the expansion of warm- 
adapted species, and severe range contractions of rangerestricted species, such as high-mountain biota (Parmesan, 2006; Parmesan and Yohe, 2003). Differential range shifts between consumers and their key resources can generate a spatial window where their interaction is no longer possible (Montoya and Raffaelli, 2010). The frequency and consequences of such spatial mismatches will likely be exacerbated if specific range shifts are not idiosyncratic but driven by broad species attributes, such as body size or mobility, thus affecting entire groups and functions (Lurgi et al., 2012; Vidal et al., 2014).

Finally, interaction frequencies can change even if the original interacting species continue to coexist in time and space but under a new biological context. Such interaction rewiring - where the original interactions are replaced by novel interactions - has been mostly documented as a response to new resources in a context of biological invasions. For example, Azorean birds and Galápagos insects were both documented to divert their consumption patterns from native resources (fruit and nectar, respectively) to the most attractive resources provided by alien plants, disrupting the native interaction networks across extant species (Heleno et al., 2013; Traveset et al., 2013).

\section{Networks' rewiring potential and functional surrogate species}

All food webs are intrinsically dynamic, constantly rearranging the interactions as new species enter or leave the network due to natural (e.g. seasonal changes) or anthropogenic (e.g. species extinctions or introductions) disturbances. Logically, the functional consequences of biodiversity declines are contingent on the ability of the remaining species to "fill the gap" created by lost species and continue to provide key ecosystem services (Kremen and Hall, 2005; Rumeu et al., 2017). Recently, these concerns have gained a new momentum with the perception of an eminent "global pollination crisis" potentially affecting both food production and natural ecosystems (Steffan-Dewenter et al., 2005). While many insect species have experienced drastic declines in recent decades (Hallmann et al., 2017), not all insect populations are declining and some even show steady increases (Bartomeus et al., 2013). The goal is now to understand if the few "winner" species can functionally replace the role of many "loser" species (McKinney and Lockwood, 1999). Evidence shows that winners can take up part of the lost services; however, this functional replacement will generally be incomplete as trophic complementarity is critical to ensure the effective delivery of most ecosystem services (Fontaine et al., 2006; Rumeu et al., 2017; Scherber et al., 2010). Such partial surrogate potential comes for example from the Balearic islands, where introduced carnivores (particularly pine martens) only partially buffer for the seed dispersal services provided by the frugivorous lizards they contributed to exterminating (Celedón-Neghme et al., 2013; Traveset et al., 2012). Although a few success stories exist, such as the Hawaiian 'ie'ie (Freycinetia arborea) which is now pollinated by the introduced white-eye (Zosterops japonica) after the extinction of several endemic birds (Cox, 1983), such system simplifications entail the loss of redundancy needed to respond to future environmental changes (Reich et al., 2012).

Even if the lost ecosystem functions cannot be fully reinstated, partially recovering at least some of the lost or degraded services might be critical for long-term ecosystem resilience (Correia et al., 2017). Such a possibility opened a new research focus exploring several alternative approaches to restoring ecosystem functionality through rewilding sensu lato (Miller and Hobbs, 2019). In this context, the use of functional surrogate taxa is actively being considered in restoration programmes to reinstate critical ecosystem functions once supported by depleted, locally extinct, or globally extinct taxa (Hansen et al., 2010). However, while such analogues can be useful conservation tools, they inevitably come both at a higher implementation cost and at a higher risk than protecting the original species.

While network rewiring potential is still very hard to predict and highly variable across interaction types, it is now clear that it must be explicitly incorporated into current species extinction models (Costa et al., 2018; Tylianakis and Morris, 2017).

\section{Forecasting food web collapse}

As the anthropogenic pressure on the biosphere continues to intensify to meet the demand of a global economy sustained by natural resources (Pacheco et al., 2018), a growing number of studies reported specific destruction thresholds at which local communities rapidly collapse (Carpenter et al., 2011; Fortuna and Bascompte, 2006). Such nonlinear transitions of biodiverse systems into simplified alternative stable states have been theoretically predicted and locally documented on a number of empirical systems including lakes, coral reefs, oceans, forests, and arid lands (Fig. 2) (reviewed in Scheffer et al., 2001). Such findings have raised concerns over an eventual planetary-scale transition threshold (Barnosky et al., 2012), beyond which abrupt changes might have important consequences for human well-being (MEA, 2005). Because such rapid regime shifts can be catastrophic and extremely hard to reverse, improving our capacity to predict them is now a pressing scientific goal (Lever et al., 2014; Staniczenko et al., 2017). Several methods have been suggested to identify potential "early-warning signals" of ecosystem collapse, including the detection of increasing variance in ecological processes, increased autocorrelation across several changes (e.g. species abundances or process rates), or increased asymmetry in the direction of those changes (Scheffer et al., 2009). The experimental collapse of 


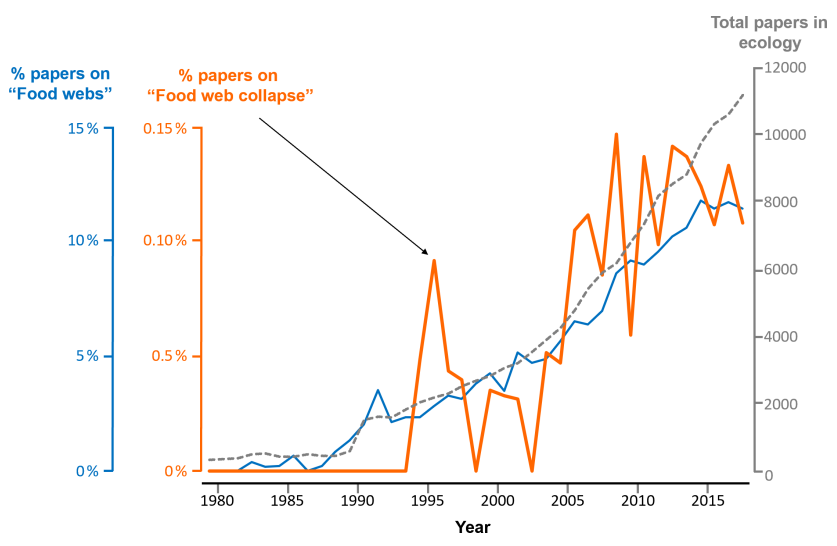

Figure 2. Proportion of all publications indexed in Web of Science that include the terms "food web", "foodweb", or "network" (blue) and those that in addition to these criteria (nested search) also include the terms "collapse" or "disruption" (orange). The search was limited to publications in English included in the topic of "ecology" (grey dashed line) published between 1980 and 2018.

lake food webs confirmed some of these early-warning signals (Carpenter et al., 2011); however many ecological systems might reach critical thresholds without warning (Hastings and Wysham, 2010). Notably, it has been shown that while high connectance and nestedness can protect pollination networks from falling apart, when a critical point is reached, pollinator populations might rapidly collapse simultaneously (Lever et al., 2014). Unfortunately, monitoring the effects of external threats such as climate change on entire food webs represents an enormous challenge even in relatively simple systems. Furthermore, while most research to date has focused on the impacts of single global change stressors, it is now clear that these can have additive, opposing, or synergistic effects, casting further uncertainty over predictions of food web stability (Scheffer et al., 2001; ValienteBanuet and Verdú, 2013). Recent developments have started to use sophisticated modelling tools to infer weighted interactions based on partial empirical data (Staniczenko et al., 2017). Although still dependent on important assumptions and still short in data, such models might provide a way towards more predictive guidelines on how food webs might respond to environmental change (Lever et al., 2014; Staniczenko et al., 2017).

\section{Concluding remarks}

Natural food webs encompass multiple interaction types between organisms with very different lifespans and home ranges that partially overlap in time and space, actively linking what might seem like disparate systems (e.g. McCauley et al., 2012). Ironically, while networks gained traction in ecology for their potential to explain complexity, the classic network approach of unipartite or bipartite interactions with well-defined borders, required for system tractability, does not satisfactorily accommodate the multi-scale structure of natural food webs (Pilosof et al., 2017). Recent methodological advances that simultaneously quantify the intra- and interlayer links under a unified multilayer approach hold great promise to jointly consider the temporal dynamics of different types of interactions in a spatially explicit context (Pilosof et al., 2017). Such analytical advances, coupled with technical advances in the detection of biotic interactions with molecular tools (Traugott et al., 2013), are likely to provide a much more powerful, inclusive, and timely tool to look beneath the bonnet of biological communities and identify the key process responsible for community assembly, functioning and collapse.

While it is intrinsically hard for ecologists to translate complex changes in communities and ecosystems into unconditional probabilities desired by policy makers (Smith, 2002), this should not obscure the relevance of the already acquired knowledge. The available studies clearly show that most global change stressors have a huge potential to disrupt trophic interactions, with particularly alarming effects in small and isolated communities such as islands, lakes, rivers, mountaintops, and anthropogenic habitat fragments (Layman et al., 2007; Traveset et al., 2016; Tylianakis et al., 2008).

It is now evident that biotic interactions are key to predict species- and community-level responses to global change and that they can no longer be ignored (Tylianakis and Morris, 2017). Shifting the conservation focus to interaction networks does not mean that species are no longer important, but rather that we are moving towards a more inclusive framework that allows us to simultaneously focus on the species we want to protect and the interactions that glue them together in functional and resilient ecosystems (Harvey et al., 2017).

Under such a framework, understanding each species' rewiring potential is critical to improve current predictions over the effects of global change on food webs (Costa et al., 2018; Tylianakis and Morris, 2017), as well as understanding the potential effect of rapid evolution in shaping rewiring potential (Parmesan, 2006).

Food web research is now confronted with the need to conciliate a double challenge: on the one hand, we need to ally more, bigger, and more detailed networks with robust experimental and modelling approaches, while on the other hand we need simplified protocols and intuitive indices that can provide simple proxies of community health that can realistically inform conservation planning and monitoring.

If the land mechanism as a whole is good then every part is good, whether we understand it or not... To keep every cog and wheel is the first precaution of intelligent tinkering (Aldo Leopold 1966).

Predicting the combined effects of multiple global change stressors on food webs remains a pressing challenge and one that will likely require considerable logistic commitments at the international level over many years. Nonetheless, this will 
be of utmost importance to preserve the ecosystem services our society depends upon (Staniczenko et al., 2017; Woodward et al., 2011). The strong body of knowledge accumulated in recent decades has shown that endangered species lists are only the most visible side of a more insidious kind of threat cast over the natural food webs that support life on Earth (Memmott, 2009; Tylianakis et al., 2010; ValienteBanuet et al., 2015). As scientists, we warn that in the face of what is likely to happen and the uncertainty in predicting when and how, the safest policy is to preserve every " $\operatorname{cog}$ and wheel".

Data availability. Raw data are available at https://doi.org/10.6084/m9.figshare.12034143.v1 (Heleno, 2020).

Author contributions. RHH led the writing with significant discussions and contributions from all authors.

Competing interests. The authors declare that they have no conflict of interest.

Financial support. This research has been supported by the Fundação para a Ciência e a Tecnologia (grant nos. UID/BIA/04004/2019 and CEECIND/00092/2017), the National Science Foundation (grant no. 1754221), and the Spanish Ministry of Science, Innovation and Universities (grant no. GCL2017-88122-P).

Review statement. This paper was edited by Jutta Stadler and reviewed by Roland Brandl and one anonymous referee.

\section{References}

Albrecht, M., Duelli, P., Schmid, B., and Muller, C. B.: Interaction diversity within quantified insect food webs in restored and adjacent intensively managed meadows, J. Anim. Ecol., 76, 10151025, 2007.

Anderson, S. H., Kelly, D., Ladley, J. J., Molloy, S., and Terry, J.: Cascading effects of bird functional extinction reduce pollination and plant density, Science, 331, 1068-1071, 2011.

Barnosky, A. D., Matzke, N., Tomiya, S., Wogan, G. O., Swartz, B., Quental, T. B., Marshall, C., McGuire, J. L., Lindsey, E. L., and Maguire, K. C.: Has the Earth's sixth mass extinction already arrived?, Nature, 471, 51-57, 2011.

Barnosky, A. D., Hadly, E. A., Bascompte, J., Berlow, E. L., Brown, J. H., Fortelius, M., Getz, W. M., Harte, J., Hastings, A., Marquet, P. A., Martinez, N. D., Mooers, A., Roopnarine, P., Vermeij, G., Williams, J. W., Gillespie, R., Kitzes, J., Marshall, C., Matzke, N., Mindell, D. P., Revilla, E., and Smith, A. B.: Approaching a state shift in Earth's biosphere, Nature, 486, 52-58, 2012.

Bartomeus, I., Ascher, J. S., Gibbs, J., Danforth, B. N., Wagner, D. L., Hedtke, S. M., and Winfree, R.: Historical changes in north- eastern US bee pollinators related to shared ecological traits, $\mathrm{P}$. Natl. Acad. Sci. USA, 110, 4656-4660, 2013.

Bascompte, J.: Disentangling the Web of Life, Science, 325, 416419, 2009.

Bascompte, J. and Jordano, P.: Plant-animal mutualistic networks: The architecture of biodiversity, Annu. Rev. Ecol. Evol. Syst., 38 , 567-593, 2007.

Bascompte, J. and Jordano, P.: Mutualistic networks, Princeton University Press, 2013.

Bascompte, J., Jordano, P., Melian, C. J., and Olesen, J. M.: The nested assembly of plant-animal mutualistic networks, P. Natl Acad. Sci. USA, 100, 9383-9387, 2003.

Bascompte, J., Jordano, P., and Olesen, J. M.: Asymmetric coevolutionary networks facilitate biodiversity maintenance, Science, 312, 431-433, 2006.

Bidartondo, M. I.: The evolutionary ecology of myco-heterotrophy, New Phytol., 167, 335-352, 2005.

Carpenter, S. R., Cole, J. J., Pace, M. L., Batt, R., Brock, W., Cline, T., Coloso, J., Hodgson, J. R., Kitchell, J. F., and Seekell, D. A.: Early warnings of regime shifts: a whole-ecosystem experiment, Science, 332, 1079-1082, 2011.

Ceballos, G., Ehrlich, P. R., Barnosky, A. D., García, A., Pringle, R. M., and Palmer, T. M.: Accelerated modern human-induced species losses: Entering the sixth mass extinction, Sci. Adv., 1, e1400253, https://doi.org/10.1126/sciadv.1400253, 2015.

Celedón-Neghme, C., Traveset, A., and Calviño-Cancela, M.: Contrasting patterns of seed dispersal between alien mammals and native lizards in a declining plant species, Plant Ecol., 214, 657667, 2013.

Correia, M., Timóteo, S., Rodríguez-Echeverría, S., Mazars-Simon, A., and Heleno, R.: Refaunation and the reinstatement of the seed-dispersal function in Gorongosa National Park, Conserv. Biol., 31, 76-85, 2017.

Costa, J. M., Ramos, J. A., da Silva, L. P., Timóteo, S., Andrade, P., Araújo, P. M., Carneiro, C., Correia, E., Cortez, P., and Felgueiras, M.: Rewiring of experimentally disturbed seed dispersal networks might lead to unexpected network configurations, Basic Appl. Ecol., 30, 11-22, 2018.

Cox, P. A.: Extinction of the Hawaiian avifauna resulted in a change of pollinators for the ieie, Freycinetia arborea, Oikos, 1983, 195199, 1983.

Darwin, C.: On the origin of species by means of natural selection, or the preservation of favoured races in the struggle for life, John Murrey, London, 1859.

de Sassi, C., Staniczenko, P. P., and Tylianakis, J. M.: Warming and nitrogen affect size structuring and density dependence in a hostparasitoid food web, Philos. T. Roy. Soc. B, 367, 3033-3041, 2012.

Derocles, S. A., Lunt, D. H., Berthe, S. C., Nichols, P. C., Moss, E. D., and Evans, D. M.: Climate warming alters the structure of farmland tritrophic ecological networks and reduces crop yield, Mol. Ecol., 27, 4931-4946, 2018.

Elton, C. S.: The ecology of invasions by animals and plants, Methuen, London, 1958

Estes, J. A., Terborgh, J., Brashares, J. S., Power, M. E., Berger, J., Bond, W. J., Carpenter, S. R., Essington, T. E., Holt, R. D., and Jackson, J. B.: Trophic downgrading of planet Earth, Science, 333, 301-306, 2011. 
Faeth, S. H., Warren, P. S., Shochat, E. and Marussich, W. A. Trophic dynamics in urban communities, BioScience, 55, 399407, 2005.

Fontaine, C., Dajoz, I., Meriguet, J., and Loreau, M.: Functional diversity of plant-pollinator interaction webs enhances the persistence of plant communities, PLoS Biol., 4, 129-135, 2006.

Fortuna, M. A. and Bascompte, J.: Habitat loss and the structure of plant-animal mutualistic networks, Ecol. Lett., 9, 278-283, 2006.

Gardner, J. L., Peters, A., Kearney, M. R., Joseph, L., and Heinsohn, R.: Declining body size: a third universal response to warming?, Trends Ecol. Evol., 26, 285-291, 2011.

Hallmann, C. A., Sorg, M., Jongejans, E., Siepel, H., Hofland, N., Schwan, H., Stenmans, W., Müller, A., Sumser, H., and Hörren, T.: More than 75 percent decline over 27 years in total flying insect biomass in protected areas, PloS one, 12, e0185809, https://doi.org/10.1371/journal.pone.0185809, 2017.

Hansen, D. M., Donlan, C. J., Griffiths, C. J., and Campbell, K. J.: Ecological history and latent conservation potential: large and giant tortoises as a model for taxon substitutions, Ecography, 33, 272-284, 2010.

Harvey, E., Gounand, I., Ward, C. L., and Altermatt, F.: Bridging ecology and conservation: from ecological networks to ecosystem function, J. Appl. Ecol., 54, 371-379, 2017.

Hastings, A. and Wysham, D. B.: Regime shifts in ecological systems can occur with no warning, Ecol. Lett., 13, 464-472, 2010.

Hegland, S. J., Nielsen, A., Lázaro, A., Bjerknes, A. L., and Totland, Ø.: How does climate warming affect plant-pollinator interactions?, Ecol. Lett., 12, 184-195, 2009.

Heleno, R.: Publications data set for fig. 2, figshare, https://doi.org/10.6084/m9.figshare.12034143.v1, 2020.

Heleno, R., Ceia, R., Ramos, J., and Memmott, J.: The effect of alien plants on insect abundance and biomass: a food web approach, Conserv. Biol., 23, 410-419, 2009.

Heleno, R., Ramos, J., and Memmott, J.: Integration of exotic seeds into an Azorean seed dispersal network, Biol. Invasions, 15, 1143-1154, 2013.

Heleno, R., Garcia, C., Jordano, P., Traveset, A., Gómez, J. M., Blüthgen, N., Memmott, J., Moora, M., Cerdeira, J., RodríguezEcheverría, S., Freitas, H., and Olesen, J. M.: Ecological networks: delving into the architecture of biodiversity, Biol. Lett., 10, 20131000, https://doi.org/10.1098/rsbl.2013.1000, 2014.

Heleno, R. H., Lacerda, I., Ramos, J. A., and Memmott, J.: Evaluation of restoration effectiveness: community response to the removal of alien plants, Ecol. Appl., 20, 1191-1203, 2010.

IPBES, Intergovernmental Science-Policy Platform on Biodiversity and Ecosystem Services: The IPBES Global Assessment Report on Biodiversity and Ecosystem Services, Paris, 2019.

James, A., Pitchford, J. W., and Plank, M. J.: Disentangling nestedness from models of ecological complexity, Nature, 487, 227230, 2012.

Kremen, C. and Hall, G.: Managing ecosystem services: what do we need to know about their ecology?, Ecol. Lett., 8, 468-479, 2005.

Laliberté, E. and Tylianakis, J. M.: Deforestation homogenizes tropical parasitoid-host networks, Ecology, 91, 1740-1747, 2010.

Lawton, J. H.: Webbing and WIWACS, Oikos, 72, 305-306, 1995.

Layman, C. A., Quattrochi, J. P., Peyer, C. M., and Allgeier, J. E.: Niche width collapse in a resilient top predator following ecosystem fragmentation, Ecol. Lett., 10, 937-944, 2007.
Ledger, M. E., Brown, L. E., Edwards, F. K., Milner, A. M., and Woodward, G.: Drought alters the structure and functioning of complex food webs, Nature Climate Change, 3, 223-227, 2013.

Leopold, A.: A sand county almanac, with essays on conservation from Roun River, Oxford University Press, 1966.

Lever, J. J., Nes, E. H., Scheffer, M., and Bascompte, J.: The sudden collapse of pollinator communities, Ecol. Lett., 17, 350-359, 2014.

López-Núñez, F. A., Heleno, R. H., Ribeiro, S., Marchante, H., and Marchante, E.: Four-trophic level food webs reveal the cascading impacts of an invasive plant targeted for biocontrol, Ecology, 98, 782-793, 2017.

Lurgi, M., López, B. C., and Montoya, J. M.: Novel communities from climate change, Philos. T. Roy. Soc. B, 367, 2913-2922, 2012.

Mayor, S. J., Guralnick, R. P., Tingley, M. W., Otegui, J., Withey, J. C., Elmendorf, S. C., Andrew, M. E., Leyk, S., Pearse, I. S., and Schneider, D. C.: Increasing phenological asynchrony between spring green-up and arrival of migratory birds, Scientific Reports, 7, 1902, https://doi.org/10.1038/s41598-017-02045-z, 2017.

McCann, K.: Protecting biostructure, Nature, 446, 29-29, 2007.

McCauley, D. J., DeSalles, P. A., Young, H. S., Dunbar, R. B., Dirzo, R., Mills, M. M., and Micheli, F.: From wing to wing: the persistence of long ecological interaction chains in less-disturbed ecosystems, Scientific Reports, 2, 409, https://doi.org/10.1038/srep00409, 2012.

McKinney, M. L. and Lockwood, J. L.: Biotic homogenization: a few winners replacing many losers in the next mass extinction, Trends Ecol. Evol., 14, 450-453, 1999.

MEA: Millennium Ecosystem Assessment - Ecosystems and human well-being: A synthesis, Island Press, Washington DC, USA, 2005.

Memmott, J.: Food webs: a ladder for picking strawberries or a practical tool for practical problems?, Philos. T. Roy. Soc. B, 364, 1693-1699, 2009.

Memmott, J., Waser, N. M., and Price, M. V.: Tolerance of pollination networks to species extinctions, Proc. R. Soc. B, 271, 2605-2611, 2004.

Memmott, J., Craze, P. G., Waser, N. M., and Price, M. V.: Global warming and the disruption of plant-pollinator interactions, Ecol. Lett., 10, 710-717, 2007.

Miller, J. R. and Hobbs, R. J.: Rewilding and restoration, Cambridge University Press, 2019.

Millington, S. J. and Grant, P. R.: Feeding ecology and territoriality of the cactus finch Geospiza scandens on Isla Daphne Major, Galapagos, Oecologia, 58, 76-83, 1983.

Montoya, J. M. and Raffaelli, D.: Climate change, biotic interactions and ecosystem services, The Royal Society, 2010.

Montoya, J. M., Pimm, S. L., and Solé, R. V.: Ecological networks and their fragility, Nature, 442, 257-264, 2006.

Morrison, B. M., Brosi, B. J., and Dirzo, R.: Agricultural intensification drives changes in hybrid network robustness by modifying network structure, Ecol. Lett., 23, 359-369, https://doi.org/10.1111/ele.13440, 2020.

Moya-Laraño, J., Verdeny-Vilalta, O., Rowntree, J., Melguizo-Ruiz, N., Montserrat, M., and Laiolo, P.: Climate change and ecoevolutionary dynamics in food webs, Adv. ecological research, Elsevier, 2012. 
O’Gorman, E. J., Pichler, D. E., Adams, G., Benstead, J. P., Cohen, H., Craig, N., Cross, W. F., Demars, B. O., Friberg, N., and Gislason, G. M.: Impacts of warming on the structure and functioning of aquatic communities: individual-to ecosystem-level responses, Advances in ecological research, Elsevier, 2012.

Pacheco, L. F., Altrichter, M., Beck, H., Buchori, D., and Owusu, E. H.: Economic Growth as a Major Cause of Environmental Crisis: Comment to Ripple et al., Bioscience, 68, 238-238, 2018.

Parmesan, C.: Ecological and evolutionary responses to recent climate change, Annu. Rev. Ecol. Evol. Syst., 37, 637-669, 2006.

Parmesan, C. and Yohe, G.: A globally coherent fingerprint of climate change impacts across natural systems, Nature, 421, 37-42, 2003.

Pilosof, S., Porter, M. A., Pascual, M., and Kéfi, S.: The multilayer nature of ecological networks, Nat. Ecol. Evol., 1, 0101, https://doi.org/10.1038/s41559-017-0101, 2017.

Pimm, S. L., Lawton, J. H., and Cohen, J. E.: Food web patterns and their consequences, Nature, 350, 669-674, 1991.

Plard, F., Gaillard, J.-M., Coulson, T., Hewison, A. M., Delorme, D., Warnant, C., and Bonenfant, C.: Mismatch between birth date and vegetation phenology slows the demography of roe deer, PLoS Biol., 12, e1001828, https://doi.org/10.1371/journal.pbio.1001828, 2014.

Pocock, M. J. O., Evans, D. M., and Memmott, J.: The robustness and restoration of a network of ecological networks, Science, 335, 973-977, 2012.

Pogoda, C. S., Keepers, K. G., Lendemer, J. C., Kane, N. C., and Tripp, E. A.: Reductions in complexity of mitochondrial genomes in lichen-forming fungi shed light on genome architecture of obligate symbioses, Mol. Ecol., 27, 1155-1169, 2018.

Poisot, T., Mouquet, N., and Gravel, D.: Trophic complementarity drives the biodiversity-ecosystem functioning relationship in food webs, Ecol. Lett., 16, 853-861, 2013.

Reich, P. B., Tilman, D., Isbell, F., Mueller, K., Hobbie, S. E., Flynn, D. F., and Eisenhauer, N.: Impacts of biodiversity loss escalate through time as redundancy fades, Science, 336, 589-592, 2012.

Ripple, W. J. and Beschta, R. L.: Linking a cougar decline, trophic cascade, and catastrophic regime shift in Zion National Park, Biol. Conserv., 133, 397-408, 2006.

Ripple, W. J., Estes, J. A., Beschta, R. L., Wilmers, C. C., Ritchie, E. G., Hebblewhite, M., Berger, J., Elmhagen, B., Letnic, M., and Nelson, M. P.: Status and ecological effects of the world's largest carnivores, Science, 343, 1241484, https://doi.org/10.1126/science.1241484, 2014.

Ripple, W. J., Newsome, T. M., Wolf, C., Dirzo, R., Everatt, K. T., Galetti, M., Hayward, M. W., Kerley, G. I., Levi, T., and Lindsey, P. A.: Collapse of the world's largest herbivores, Sci. Adv., 1, e1400103, https://doi.org/10.1126/sciadv.1400103, 2015.

Ripple, W. J., Estes, J. A., Schmitz, O. J., Constant, V., Kaylor, M. J., Lenz, A., Motley, J. L., Self, K. E., Taylor, D. S., and Wolf, C.: What is a trophic cascade?, Trends Ecol. Evol., 31, 842-849, 2016.

Ripple, W. J., Wolf, C., Newsome, T. M., Galetti, M., Alamgir, M., Crist, E., Mahmoud, M. I., and Laurance, W. F.: World scientists' warning to humanity: A second notice, Bioscience, 67, 10261028, 2017.

Rogers, H. S., Buhle, E. R., HilleRisLambers, J., Fricke, E. C., Miller, R. H., and Tewksbury, J. J.: Effects of an invasive preda- tor cascade to plants via mutualism disruption, Nature Commun., 8, 14557, https://doi.org/10.1038/ncomms14557, 2017.

Rohr, R. P., Saavedra, S., and Bascompte, J.: On the structural stability of mutualistic systems, Science, 345, 1253497, https://doi.org/10.1126/science.1253497, 2014.

Rumeu, B., Devoto, M., Traveset, A., Olesen, J. M., Vargas, P., Nogales, M., and Heleno, R.: Predicting the consequences of disperser extinction: richness matters the most when abundance is low, Funct. Ecol., 31, 1910-1920, 2017.

Scheffer, M., Carpenter, S., Foley, J. A., Folke, C., and Walker, B.: Catastrophic shifts in ecosystems, Nature, 413, 591-596, 2001.

Scheffer, M., Bascompte, J., Brock, W. A., Brovkin, V., Carpenter, S. R., Dakos, V., Held, H., van Nes, E. H., Rietkerk, M., and Sugihara, G.: Early-warning signals for critical transitions, Nature, 461, 53-59, 2009.

Scheffers, B. R., Joppa, L. N., Pimm, S. L., and Laurance, W. F.: What we know and don't know about Earth's missing biodiversity, Trends Ecol. Evol., 27, 501-510, 2012.

Scherber, C., Eisenhauer, N., Weisser, W. W., Schmid, B., Voigt, W., Fischer, M., Schulze, E.-D., Roscher, C., Weigelt, A., and Allan, E.: Bottom-up effects of plant diversity on multitrophic interactions in a biodiversity experiment, Nature, 468, 553-556, 2010.

Smith, L. A.: What might we learn from climate forecasts?, P. Natl. Acad. Sci., 99, 2487-2492, 2002.

Sparks, T. and Yates, T.: The effect of spring temperature on the appearance dates of British butterflies 1883-1993, Ecography, 20, 368-374, 1997.

Staniczenko, P. P., Lewis, O. T., Tylianakis, J. M., Albrecht, M., Coudrain, V., Klein, A.-M., and Reed-Tsochas, F.: Predicting the effect of habitat modification on networks of interacting species, Nature Commun., 8, 792, https://doi.org/10.1038/s41467-01700913-w, 2017.

Steffan-Dewenter, I., Potts, S. G., and Packer, L.: Pollinator diversity and crop pollination services are at risk, Trends Ecol. Evol., 20, 651-652, 2005.

Stiling, P. and Cornelissen, T.: How does elevated carbon dioxide (CO2) affect plant-herbivore interactions? A field experiment and meta-analysis of $\mathrm{CO}_{2}$-mediated changes on plant chemistry and herbivore performance, Glob. Change Biol., 13, 1823-1842, 2007.

Thompson, R. M., Brose, U., Dunne, J. A., Hall, R. O., Hladyz, S., Kitching, R. L., Martinez, N. D., Rantala, H., Romanuk, T. N., Stouffer, D. B., and Tylianakis, J. M.: Food webs: reconciling the structure and function of biodiversity, Trends Ecol. Evol., 27, 689-697, 2012.

Tilman, D., May, R. M., Lehman, C. L., and Nowak, M. A.: Habitat destruction and the extinction debt, Nature, 371, 65-66, https://doi.org/10.1038/371065a0, 1994.

Traugott, M., Kamenova, S., Ruess, L., Seeber, J., and Plantegenest, M.: Empirically characterising trophic networks: what emerging DNA-based methods, stable isotope and fatty acid analyses can offer, Adv. Ecol. Res., 49, 177-224, 2013.

Traveset, A. and Richardson, D. M.: Mutualistic interactions of invasive species, Annu. Rev. Ecol. Evol. Syst., 45, 89-113, 2014.

Traveset, A., González-Varo, J. P., and Valido, A.: Longterm demographic consequences of a seed dispersal disruption, Proc. R. Soc. B, 279, 3298-3303, https://doi.org/10.1098/rspb.2012.0535, 2012. 
Traveset, A., Heleno, R., Chamorro, S., Vargas, P., McMullen, C., Castro-Urgal, R., Nogales, M., Herrera, H. W., and Olesen, J. M.: Invaders of pollination networks in the Galápagos Islands: emergence of novel communities, Proc. R. Soc. B, 280, 20123040, https://doi.org/10.1098/rspb.2012.3040, 2013.

Traveset, A., Chamorro, S., Olesen, J. M., and Heleno, R.: Space, time and aliens: charting the dynamic structure of Galápagos pollination networks, AoB Plants, 7, plv068, https://doi.org/10.1093/aobpla/plv068, 2015.

Traveset, A., Tur, C., Trøjelsgaard, K., Heleno, R., Castro-Urgal, R., and Olesen, J. M.: Global patterns of mainland and insular pollination networks, Glob. Ecol. Biogeogr., 25, 880-890, 2016.

Traveset, A., Araújo, M. B., and Marquet, P. A.: Cambio global y su impacto sobre las redes de interacciones ecológicas, in: Cambio Global. Una mirada desde Iberoamérica, edited by: Marquet, P. A., Valladares, F., Magro, S., Gaxiola, A., and Enrich-Prast, A., ACCI Ediciones, 2018.

Tylianakis, J. M. and Morris, R. J.: Ecological networks across environmental gradients, Annual Review of Ecology, Evolution, and Systematics, 48, 25-48, 2017.

Tylianakis, J. M., Tscharntke, T., and Lewis, O. T.: Habitat modification alters the structure of tropical host-parasitoid food webs, Nature, 445, 202-205, 2007.

Tylianakis, J. M., Didham, R. K., Bascompte, J., and Wardle, D. A.: Global change and species interactions in terrestrial ecosystems, Ecol. Lett., 11, 1351-1363, 2008.

Tylianakis, J. M., Laliberté, E., Nielsen, A., and Bascompte, J.: Conservation of species interaction networks, Biol. Conserv., 143, 2270-2279, 2010.

UCS: https://www.ucsusa.org/about/1992-world-scientists.html (last access: February 2020), 1992.

UN: Transforming our world: The 2030 Agenda for Sustainable Development, United Nations General Assembly, 2015.

Valiente-Banuet, A. and Verdú, M.: Human impacts on multiple ecological networks act synergistically to drive ecosystem collapse, Front. Ecol. Environ., 11, 408-413, 2013.

Valiente-Banuet, A., Aizen, M. A., Alcántara, J. M., Arroyo, J., Cocucci, A., Galetti, M., García, M. B., García, D., Gómez, J. M., Jordano, P., Medel, R., Navarro, L., Obeso, J. R., Oviedo, R., Ramírez, N., Rey, P. J., Traveset, A., Verdú, M., and Zamora, R.: Beyond species loss: the extinction of ecological interactions in a changing world, Funct. Ecol., 29, 299-307, 2015.
Verdú, M. and Valiente-Banuet, A.: The nested assembly of plant facilitation networks prevents species extinctions, Am. Nat., 172, 751-760, 2008.

Vidal, M. M., Hasui, E., Pizo, M. A., Tamashiro, J. Y., Silva, W. R., and Guimarães Jr., P. R.: Frugivores at higher risk of extinction are the key elements of a mutualistic network, Ecology, 95, 3440-3447, 2014.

Vilà, M., Bartomeus, I., Dietzsch, A. C., Petanidou, T., SteffanDewenter, I., Stout, J. C., and Tscheulin, T.: Invasive plant integration into native plant-pollinator networks across Europe, Proc. R. Soc. B, 276, 3887-3893, 2009.

Visser, M. E., Holleman, L. J., and Gienapp, P.: Shifts in caterpillar biomass phenology due to climate change and its impact on the breeding biology of an insectivorous bird, Oecologia, 147, 164$172,2006$.

Watts, D. J. and Strogatz, S. H.: Collective dynamics of 'smallworld' networks, Nature, 393, 440-442, 1998.

Williams, R. Network3D Software, Microsoft Research, Cambridge UK, 2010.

Woodward, G., Benstead, J. P., Beveridge, O. S., Blanchard, J., Brey, T., Brown, L., Cross, W. F., Friberg, N., Ings, T. C., Jacob, U., Jennings, S., Ledger, M. E., Milner, A. M., Montoya, J. M., O’Gorman, E., Olesen, J. M., Petchey, O. L., Pichler, D. E., Reuman, D. C., Thoompson, M. S., Veen, F. J. F. V., and Yvon-Durocher, G.: Ecological networks in a changing climate, Adv. Ecol. Res., 42, 71-138, https://doi.org/10.1016/B978-0-12381363-3.00002-2, 2011.

Woodward, G., Brown, L. E., Edwards, F. K., Hudson, L. N., Milner, A. M., Reuman, D. C., and Ledger, M. E.: Climate change impacts in multispecies systems: drought alters food web size structure in a field experiment, Philos. T. Roy. Soc. B, 367, 2990 2997, 2012.

Zavaleta, E. S., Thomas, B. D., Chiariello, N. R., Asner, G. P., Shaw, M. R., and Field, C. B.: Plants reverse warming effect on ecosystem water balance, P. Natl. Acad. Sci., 100, 9892-9893, 2003. 